\title{
SPINK7 Expression Changes Accompanied by HER2, P53 and RB1 Can Be Relevant to Predict Oral Squamous Cell Carcinoma at Molecular Level
}

\section{Gina Pennacchiotti}

Area Medicina Oral Departamento de Patología Facultad de Odontología Universidad de Chile. Av.

Olivos 243, Independencia, RM CP8320000

\section{Fabio Valdés Garrido}

Instituto Nacional del Cáncer. Av. Profesor Zañartu 1010, Independencia, RM CP8320000.

\section{Wilfredo González-Arriagada}

CIICOM, Facultad de Odontología, Universidad de Valparaíso. Av. Altamirano Subida Carvallo 211.

CP2390302

\section{Héctor Montes}

Departamento de cirugía cabeza-cuello Clínica Montes. Ituzaingo 1446, Capital, Mendoza, CP5500

Judith Parra

Servicio de Medicina Bucal (SEMEB), Facultad de Odontología, Universidad Nacional de Cuyo (FOdontoUNCuyo). Centro Universitario CIT5500, Mendoza, CP5500

\section{Valeria Guida}

Servicio de Medicina Bucal (SEMEB), Facultad de Odontología, Universidad Nacional de Cuyo (FOdontoUNCuyo). Centro Universitario CIT5500, Mendoza, CP5500

\section{Silvina Gómez}

Instituto de Medicina y Biología Experimental de Cuyo (IMBECU) CCT-Mendoza CONICET, Universidad Nacional de Cuyo (UNCuyo). Av. Adrián Ruiz Leal w/n, Mendoza, CP5500

\section{Martín Guerrero-Gimenez}

Instituto de Medicina y Biología Experimental de Cuyo (IMBECU) CCT-Mendoza CONICET, Universidad Nacional de Cuyo (UNCuyo). Av. Adrián Ruiz Leal w/n, Mendoza, CP5500

\section{Juan Fernandez-Muñoz}

Instituto de Medicina y Biología Experimental de Cuyo (IMBECU) CCT-Mendoza CONICET, Universidad Nacional de Cuyo (UNCuyo). Av. Adrián Ruiz Leal w/n, Mendoza, CP5500

\section{Felipe Zopino}

Instituto de Medicina y Biología Experimental de Cuyo (IMBECU) CCT-Mendoza CONICET, Universidad Nacional de Cuyo (UNCuyo). Av. Adrián Ruiz Leal w/n, Mendoza, CP5500

\section{Rubén Carón}

Instituto de Medicina y Biología Experimental de Cuyo (IMBECU) CCT-Mendoza CONICET, Universidad Nacional de Cuyo (UNCuyo). Av. Adrián Ruiz Leal w/n, Mendoza, CP5500 


\section{Marcelo Ezquer}

Centro de Medicina Regenerativa (CMR), Facultad de Medicina, Universidad del Desarrollo-Clínica Alemana (FM, UDD-CAS). Av Las Condes 12.438, Lo Barnechea, CP7690000

\section{Ricardo Fernández-Ramires}

Facultad de Odontología, Universidad Mayor (UMayor). Avda Libertador Bernardo O`Higgins 2013. RM, CP8320000

\section{Flavia Bruna ( $\nabla$ flabruna@gmail.com )}

Instituto de Medicina y Biología Experimental de Cuyo (IMBECU) CCT-Mendoza CONICET, Universidad Nacional de Cuyo (UNCuyo). Av. Adrián Ruiz Leal w/n, Mendoza, CP5500

\section{Research Article}

Keywords: Oral squamous cancer, early detection, molecular biomarker, SPINK7, epithelial cells, Oral epithelial dysplasia.

Posted Date: November 30th, 2020

DOI: https://doi.org/10.21203/rs.3.rs-108017/v1

License: (c) (i) This work is licensed under a Creative Commons Attribution 4.0 International License. Read Full License

Version of Record: A version of this preprint was published at Scientific Reports on March 25th, 2021. See the published version at https://doi.org/10.1038/s41598-021-86208-z. 
SPINK7 expression changes accompanied by HER2, P53 and RB1 can be relevant to predict oral squamous cell carcinoma at molecular level

Gina Pennacchiotti, DMD ${ }^{1,7}$; Fabio Valdés Garrido, $\mathrm{MD}^{2}$; Wilfredo A González-Arriagada, $\mathrm{PhD}^{3}$; Héctor F Montes, $\mathrm{MD}^{4}$; Judith MR Parra, $\mathrm{DMD}^{5}$; Valeria A Guida, $\mathrm{DMD}^{5}$; Silvina E Gómez, $\mathrm{Bsc}^{6}$; Martín E Guerrero-Gimenez, MD; Juan M Fernandez-Muñoz, Bsc ${ }^{6}$; Felipe CM Zopino, PhD ${ }^{6}$; Rubén W Carón, $\mathrm{PhD}^{6}$; Marcelo E Ezquer, $\mathrm{PhD}^{7}$; Ricardo Fernández-Ramires, $\mathrm{PhD}^{8}$ and Flavia $\mathrm{A}$ Bruna, $8 \mathrm{PhD}^{5,6,7}$.

\section{Author's details}

11 1. Area Medicina Oral Departamento de Patología Facultad de Odontología Universidad de Chile. 12 Av. Olivos 243, Independencia, Región Metropolitana, Santiago, Chile. CP8320000.

13 2. Instituto Nacional del Cáncer. Av. Profesor Zañartu 1010, Independencia, Región Metropolitana, 14 Santiago, Chile. CP8320000.

15 3. ClICOM, Facultad de Odontología, Universidad de Valparaíso. Av. Altamirano Subida Carvallo 16 211. Valparaíso, Chile. CP2390302.

17 4. Departamento de cirugía cabeza-cuello Clínica Montes. Ituzaingo 1446, Capital, Mendoza, 18 Argentina. CP5500.

19 5. Servicio de Medicina Bucal (SEMEB), Facultad de Odontología, Universidad Nacional de Cuyo 20 (FOdonto-UNCuyo). Centro Universitario CIT5500, Capital, Mendoza, Argentina. CP5500.

21 6. Instituto de Medicina y Biología Experimental de Cuyo (IMBECU) CCT-Mendoza CONICET, 22 Universidad Nacional de Cuyo (UNCuyo). Av. Adrián Ruiz Leal w/n, Capital, Mendoza, Argentina. 23 CP5500.

24 7. Centro de Medicina Regenerativa (CMR), Facultad de Medicina, Universidad del Desarrollo25 Clínica Alemana (FM, UDD-CAS). Av Las Condes 12.438, Lo Barnechea. Santiago, Chile. 26 CP7690000.

27 8. Facultad de Odontología, Universidad Mayor (UMayor). Avda Libertador Bernardo O`Higgins 2013.

28 Región Metropolitana, Santiago, Chile. CP8320000.

\section{Corresponding author: Flavia A Bruna}

31 Room: Laboratory of hormones and cancer biology, Instituto de Medicina y Biología Experimental de 32 Cuyo (IMBECU) CCT-Mendoza CONICET, Universidad Nacional de Cuyo (UNCuyo).

33 Address: Av Adrián Ruiz Leal w/n, Mendoza Capital, Argentina

34 Postal code: 5500

35 Email: flabruna@gmail.com / fbruna@mendoza-conicet.gob.ar

36 Phone: +54 2615244154

\section{Abstract}

39 The oral squamous cell carcinoma (OSCC) affects patients worldwide with a high morbidity rate. 40 Changes of SPINK7 in precancerous lesions could promote oncogenesis. Our aim was to evaluate 
SPINK7 as a potential molecular biomarker predictive of OSCC stages, compared with: HER2, TP53, RB1, NFKB and CYP4B1. Oral biopsies from patients with dysplasia $(n=33)$, less invasive $(n=28)$ and highly invasive OSCC $(n=18)$ were used. 20 cases with a clinical suspicion but normal mucosa confirmed were the control. Gene levels of SPINK7, P53, RB, NFKB and CYP4B1 were quantified by qPCR. SPINK7 levels were correlated with a cohort of 330 patients from the TCGA. Also, SPINK7, HER2, TP53, and RB1, were evaluated by immunohistofluorescence. One-way Kruskal-Wallis test and Dunn's post-hoc with a $\mathrm{p}<0.05$ significance was used to data analyze. In OSCC, SPINK7 expression was down regulated and $P 53, R B, N F K B$ and $C Y P 4 B 1$ were up regulated $(\mathrm{p}<0.001)$. Also, SPINK7 was diminished in TCGA patients $(p=2.10 \mathrm{e}-6)$. In less invasive OSCC, SPINK7 and HER2 proteins were decreased and TP53 and RB1 increased respect to others groups $(p<0.05)$. Our results suggest that SPINK7 changes accompanied of HER2, P53 and RB1 can be used to classify the molecular stage of OSCC lesions, allowing a diagnosis to molecular and histopathological level.

Key words: Oral squamous cancer; early detection; molecular biomarker; SPINK7; epithelial cells; Oral epithelial dysplasia.

Introduction. Oral squamous cell carcinoma (OSCC) is the most common malignancy of the head and neck, with a high morbidity rate $(37.8 \%)$ five years after diagnosis ${ }^{1}$. Despite great improvement in treatment and therapy, prognosis remains poor ${ }^{2}$. Furthermore, OSCC often causes dysfunctions and aesthetic disorders, and have a high incidence of cervical lymph node metastasis, worsen patients quality of life ${ }^{3}$. Several tumor biomarkers have been suggested as predictive for OSCC prognosis with poor outcome ${ }^{4}$, however, specific molecular prognostic factors have only been partially identified ${ }^{5}$. The pattern of invasion (POI) presented by Brandwein-Gensler et al., classifies the $\mathrm{POI}$ in five types ${ }^{6}$, and has been validated as an independent prognostic factor in oral cancer ${ }^{7}$. However, it is necessary to identify changes in proteins and genes, to improve diagnostic strategies in precancerous, invasive and metastatic stages ${ }^{8}$.

67 One of the cancer hallmarks is the alteration of molecules related to cell adhesion and migration ${ }^{9}$.

68 Adhesion molecules play a central role in pathogenesis and progression of malignant tumors ${ }^{10}$. Serine Peptidase Inhibitor, Kazal Type 7 (SPINK7, ECRG2) belongs to a family of 13 members (113) of proteins with inhibitory Serine Peptidase activity identified in 1998 in esophageal tissue ${ }^{11}$. This novel tumor suppressor gene was identified as a tumor suppressor gene by comparing normal esophageal epithelia and primary squamous cell carcinomas tissues ${ }^{12,13}$. It has been reported that

73 SPINK7 inhibits tumor cells growth, promotes cell apoptosis, and inhibits cancer cell migration, 74 invasion and metastasis in vitro ${ }^{14,15}$.

75 The HER2, P53, RB1, NFKB and CYP4B1 genes and their proteins have been described altered in 76 OSCC carcinogenesis ${ }^{16}$. The human epidermal growth factor receptors (HER/EGFR) are a family of trans membrane tyrosine kinase receptors comprising 1 to 4 (HER1-4) ${ }^{17}$. The overexpression of HER 78 is involved in the development of oncogenesis, including OSCC, through regulating different cellular 79 pathways. HER2 (also known as C-erbB-2/ERBB2/ErbB2) plays a critical role in the cell proliferation, 80 survival, migration, angiogenesis, and metastasis through a variety of intracellular signaling cascades 
such as MAPK/ERK1/2 and Pi3K/Akt ${ }^{18,19}$. An imbalance in these pathways can lead to permanent

82 activation ${ }^{20,21}$. Studies have established a marked correlation between HER2 expression and the 83 poor survival of OSCC patients ${ }^{22}$. It has been reported that the SPINKs protein family share $50 \%$ of 84 homology to EGF molecule and can interact by binding to EGFR, activating EGFR downstream AKT 85 signaling pathway, inducing epithelial mesenchymal transition ${ }^{23}$. The SPINK6 protein is secreted and 86 act as a functional regulator of nasopharyngeal carcinoma cells metastasis through the bound to 87 EGFR extracellular domain ${ }^{23}$.

88 In cancer cells, tumor-suppressor genes like Protein 53 (TP53) and Retinoblastoma (RB1) are 89 inactivated by mutation, deletion and methylation ${ }^{24}$. It is well established that TP53 is a genome 90 guardian and plays a pivotal role in regulating the cell cycle, cellular differentiation, DNA repair, and 91 apoptosis ${ }^{25,26}$. Somatic mutations in TP53 are detected in $>60 \%$ of OSCC and in $10 \%$ of oral 92 dysplasia ${ }^{27}$. Recently, Genome Wide Association Study data has shown that TP53 is usually mutated 93 in papillomavirus-negative OSCC patients ${ }^{28}$. The TP53 mutations in OSCC (classified in low- and 94 high-risk missense mutations) are associated with resistance to Cisplatin, distant metastasis and poor 95 prognosis ${ }^{29-31}$. The overall survival of TP53-mutant OSCC patients is also markedly worse than 96 patients with TP53 wild-type ${ }^{32}$. Previous studies reported that SPINK7 also participates in 97 centrosome amplification in TP53-dependent manner and has a role in maintaining chromosome 98 stability ${ }^{33}$. Other gene altered is RB1 that plays a key role in the regulation of cell cycle and 99 differentiation. Its active form is phosphorylated ( $p R B 1$ ), acts a regulator at the G1-S restriction point 100 arresting the cell cycle ${ }^{34}$. Mutations lead to functional pRB1 inactivation and failure of growth and 101 tumor suppression control ${ }^{35}$.

102 Another molecule altered in carcinogenesis is the Nuclear factor-KB (NFKB), this is a proinflammatory 103 transcription factor that plays a pivotal role in initiation and progression of the cancer ${ }^{36}$. NFKB is 104 constitutively activated in OSCCs and is involved in promoting the invasive characteristics ${ }^{37}$. 105 Regarding the cell detoxification machinery, Cytochrome P450 enzyme family (CYP450) is one of the 106 most important ${ }^{38,39}$. Their activity consists in catalyzing reactions that participate in both biosynthesis 107 and degradation of drug metabolism and xenobiotic biotransformation pathways ${ }^{40}$. These enzymes 108 can participate indirectly in the OSCC carcinogenesis through activation and detoxification of these 109 compounds ${ }^{38,40}$.

110 The Cancer Genome Atlas (TCGA) is an important tool to provide expression profiles from cancer 111 patient samples and the associated clinical-pathological data for $>30$ human cancer types ${ }^{41}$. 112 However, there are few studies on genome-wide profiling of OSCC tumors.

113 The aim of this work was to determine if SPINK7 gene expression is associated to molecules altered 114 in cancer p53, RB1, NFKB, CYP4B1 and HER2 as a good biomarker candidate of premalignant 115 epithelial oral lesions and OSCC stages, having potential therapeutic applications (early detection 116 and targeted therapies).

\section{7}

\section{Results.}

119 Study population data. Of a total of 71 Caucasian patients with oral dysplasia or OSCC were 120 consent and enrolled in the present study. The average age was 52 years. The predominant gender 
121 was male. Of the total of patients $30 \%$ had no smoking habits, $20 \%$ were light smokers (less than 10 122 cigarettes daily), $40 \%$ heavy smokers (more than 10 cigarettes daily) and a $10 \%$ did not specify if 123 they had smoking habits. Being the most frequent tumor location the tongue ride (80\%) (Table 1).

124 The oral epithelium changes among OSCC stages. To analyze epithelial changes in OSCC 125 progression, the oral biopsies were evaluated by H\&E and classified in dysplasia, less invasive and 126 highly invasive OSCC. We found 33 cases of dysplasia, 28 cases of less invasive OSCC and 18 127 cases of highly invasive OSCC. In all dysplasia cases, the tissue did not show loss of basement 128 membrane continuity or presence of epithelial cells invading the stroma, although an increase in 129 epithelial cell layers and presence of mild leukocyte infiltrate was observed (Figure 1A-D). In the 130 OSCC groups both (less invasive and highly invasive), showed more than 5 layers of epithelial cells, 131 hyperchromatism, cellular atypias and presence of keratin pearls, loss of continuity of the basement 132 membrane and severe leukocyte infiltrate (Figure 1B-C-E-F). In the highly invasive OSCC group, 133 epithelial cell nests were observed in the stroma, total epithelial disorganization, keratin pearls and 134 leucocyte infiltration severe. These results were correlated with poor prognosis (Figure 1C). The 135 inserts (black square) shown at high magnification the oral epithelium changes among the OSCC 136 stages (Figure 1D-F).

137 SPINK7 generate a distinctive molecular signature among the OSCC stages. To evaluate the 138 molecular status of the biopsies among the OSCC stages, we assessed the gene expression of 139 SPINK7 with reported altered genes in carcinogenesis: TP53, RB1, NFKB and CYP4B1 in the groups.

140 We found SPINK7 progressively down-regulated in oral dysplasia and OSCC groups respect to 141 control ( $p<0.001)$. Regarding TP53, RB1, NFKB and CYP4B1 all were upregulated in OSCC groups 142 with respect to dysplasia and control groups $(p<0.001)$. Additionally, with exception of SPINK7, we 143 observed differential expression levels of the rest of the genes between less invasive OSCC and 144 highly invasive OSCC groups (TP53, RB1 and NFKB ( $<<0.05)$; CYP4B1 $p<0.001)$ ) (Figure 2A). The 145 differences observed regarding the gene expression among the groups were correlated with a poor 146 prognosis.

147 SPINK7 was down regulated in patients from TCGA. To evaluate if the SPINK7 gene expression 148 profile observed in our study population was reproducible with other cohort of OSCC patients, we 149 analyzed the gene expression levels in 581 patients with OSCC from the TCGA (primary tissue) and 150 the results were compared with normal subjects data (normal tissue) through in silico analysis ${ }^{42}$. The 151 results were graphed as box plot comparing the gene expression of normal group (box plot blue) 152 versus primary tumors group (box plot yellow) showing significant downregulation of SPINK7 $\mathrm{p}=2.10^{\mathrm{e}-}$ $153{ }^{06}$ and this result was correlated with our results respect to SPINK7 gene expression (Figure 3A).

154 SPINK7 does not show mutations according to TCGA mutation gene profile. To understand if 155 the differential expression of SPINK7 among the OSCC stages is related to a mutational profile, we 156 analyzed in silico mutations described to date of a cohort of 329 patients from TCGA database. We 157 identified 15 genes with differential mutations rate associated to OSCC, being gene of interest 158 SPINK7 included in the analysis. We found that TP53 was the gene with the highest number of 159 mutations in the OSCC cohort, being mutated in $69 \%$ of patients (Figure 3B). The most frequent type 160 of variant was missense mutations followed by nonsense mutations, frameshift deletions, and multi 
161 hits mutations. TTN gene showed a mutation rate of $34 \%$, FAT1 (26\%), CDKN2A (22\%), NOTCH1

162 (18\%), PIK3CA and MUC16 (16\%), CASP8 (15\%), SYNE1 (14\%), CSMD3 and PCL2 (13\%) and

163 finally, KMT2D, LRP1B, DNAH5 and FLG genes were mutated in $12 \%$ of the patients. On the other

164 hand, with a more stable mutational profile, we found RB1 (mutated in $2 \%$ of the samples), HER2,

165 NFKB1 and CYP4B1 (1\%) of the cohort. Finally, we found that the SPINK7 is a genomic stable gene,

166 which showed no mutations in none of the cases analyzed (Figure 3B).

167 SPINK7 and HER2 change differentially among the OSCC stages. It has been reported previously

168 that SPINKs proteins can interact with HER2 receptor ${ }^{43}$. We evaluated the presence and abundance

169 of SPINK7 among the different groups and its correlation with HER2 protein by confocal microscopy.

170 We found that SPINK7 (green signal) and HER2 (red signal) were significantly decreased in less

171 invasive OSCC group compared with dysplasia and highly invasive OSCC groups $(p<0.05)$. On

172 another hand, the highly invasive OSCC group showed SPINK7 protein levels similar to dysplasia

173 and no significant differences were found. Regarding HER2, it was found significantly reduced in less

174 invasive OSCC compared to the other groups. Meanwhile, the highly invasive OSCC group showed

175 a significant increase of HER2 compare to less invasive OSCC $(p<0.001)$, being similar to the

176 dysplasia group (Figure 4A-B).

177 SPINK7 and HER2 were colocalized. Due to the overlapping of signals (yellow signal) between

178 SPINK7 (green signal) and HER2 (red signal) in confocal microscopy we evaluated at high

179 magnification images (120X digital zoom) through colocalization analysis. The intensity variability of

180 both channels was statistically evaluated using Pearson's coefficient of 1 as positive result $(r=0,99)$.

181 Yellow versus red and green pixels were quantified yielding a co-occurrence value of $56.58 \%$ (Figure

182 4C).

183 TP53 and pRB1 change differentially among the OSCC stages. To evaluate cell cycle regulators

184 in the OSCC, we analyzed TP53 and PRB1 protein levels among the groups by confocal microscopy.

185 The less invasive OSCC group showed a significant increase of TP53 and pRB1 compared with

186 dysplasia and highly invasive OSCC groups $(p<0.05)$. Regarding the highly invasive OSCC group,

187 both proteins (TP53 and pRB1) significantly decreased respect to the other groups $(p<0.001)$ (figure

188 5A-B).

190 Discussion. The oral squamous cell carcinoma has a high morbidity rate in the world ${ }^{1}$. Despite the

191 progress in research and therapy, survival has not improved significantly in the last decades ${ }^{44}$. The

192 biomarkers study aims to understand the role of genetic and lifestyle factors of the tumor biology

193 included the OSCC ${ }^{45}$. We studied changes in proteins related with some of the cancer hallmarks

194 (cell survival, cell cycle, inflammation, metastasis and metabolism) to stratify molecularly oral

195 precancerous and cancerous lesions ${ }^{46}$. Currently, the gold standard of OSCC diagnosis is the biopsy,

196 however, the results are observer-dependent and subjective ${ }^{44,47}$.

197 The current study is reporting the SPINK7 expression changes among the OSCC stages and we 198 propose this protein as a "new biomarker" associated with the natural progression of the OSCC. We 199 found differences among the oral epithelial organization in dysplasia and less or highly invasive 200 OSCC groups, and these results were correlated with the literature ${ }^{48,49}$, showing a differential gene 
201 expression profile by qPCR analysis with a distinctive "molecular signature" in each stage. We found 202 SPINK7 significantly down regulated at dysplasia and OSCC compared with control group. 203 Meanwhile TP53, RB1, NFKB and CYP4B1 were significantly up regulated at OSCC stages compare 204 with dysplasia and control groups. The results obtained by SPINK7 in our study population were 205 compared with a cohort of 541 patients from the TGCA database ${ }^{50}$. The comparative analysis 206 showed that SPINK7 was significantly down regulated in patients with OSCC compare to normal 207 tissue and this could be related with the advance grade of the malignant lesion ${ }^{51}$. Additionally, we 208 analyzed the mutation profile of genes described in TCGA altered in OSCC included SPINK7, TP53, $209 R B 1, N F K B$ and CYP4B1. We found that TP53 showed a high mutation rate in OSCC meanwhile 210 SPINK7 was the most stable without any mutation described. These results suggest that the 211 downregulation of the gene would be related to other mechanisms, not associated to TP53 gene, and 212 need to be explored in a future.

213 Due the SPINK's protein family is related with extracellular matrix remodeling and cell migration 214 regulation ${ }^{43}$. We evaluated the abundance of SPINK7 and HER2 and if there are correlation between 215 them, because has been reported that SPINK7 shares $50 \%$ of homology with EGF ${ }^{43}$. We found 216 SPINK7 up regulated in the highly invasive OSCC group, these results were similar to previous 217 studies describing that SPINK6 was up regulated in highly metastatic tumors ${ }^{43}$. SPINK6 regulate the 218 metastasis via EGFR signaling and their expression levels change during the carcinogenesis ${ }^{52}$. 219 Interestingly SPINK7 and HER2 were overexpressed in the highly invasive OSCC compared with 220 less invasive OSCC. Additionally the SPINK7 and HER2 colocalization analysis showed that both 221 proteins are close suggesting interaction, however subsequent tests with a larger sample size are 222 necessary to evaluate and understand its interaction or co-compartmentalization ${ }^{51}$. The differential 223 expression of the studied proteins among the OSCC stages could be related with disorganization of 224 the oral epithelium and to a non-functional protein or absence of their ligands, but it needs to be 225 explored in more detail in the future ${ }^{53}$. The differential proteins expression among the stages allowed 226 stratifying the groups to molecular and histological levels correlated with prognosis. It has been 227 reported in esophageal cancer that cells treated with a siRNA for SPINK1 were resistant to the 228 antitumoral drug Cisplatin ${ }^{54}$. This could be interesting in order to stratify the patients who respond, 229 or not, to the standard chemotherapy.

230 Regarding the studied cell cycle factors, TP53 and pRB1, we found through confocal microscopy 231 analysis that both proteins were upregulated in the less invasive OSCC respect to dysplasia; 232 meanwhile in the highly invasive OSCC both were downregulated, which consistent with previous 233 studies ${ }^{55}$. These could be explained according to the TCGA in silico analysis with the high rate of 234 mutation profile that both genes showed in OSCC. These results suggest that in OSCC, TP53 and 235 pRB1 are present but non-functional and this could be related with a more aggressive tumor ${ }^{55}$.

236 Our results suggest that the changes in the expression of SPINK7 can be used to predict the 237 molecular stage of the OSCC lesions. This molecule could be a new "potential" biomarker. Futures 238 studies are needed to validate this novel tumor suppressor gene that could be applied as a possible 239 early diagnostic method to precancerous oral lesions and OSCC. 
242 Study population. Patients with suspected oral lesions of OSCC were enrolled. After signing the 243 informed consent, the subjects were interviewed using a standard questionnaire that requested 244 information about socio-demographic, medical, and lifestyle factors. The patients from Department of 245 Head and Neck surgery of The National Cancer Institute, Dental school of Universidad de Valparaíso, 246 Dental school of Universidad del Desarrollo (Chile), The Hospital Lencinas and the Servicio de 247 Estomatología y Medicina Bucal Dental school, Universidad Nacional de Cuyo (Argentina); received 248 a routine intraoral examination and oral mucosal biopsies were taken and classified according to the 249 diagnosis and POI in three groups: oral epithelial dysplasia, less invasive OSCC (POI type 1 and 2) 250 and invasive OSCC (POI type 3, 4 and 5) group. Seventy-one cases of primary OSCC diagnosed 251 over a period of 2 years (2017-2019) were included in the study. None of the patients had received 252 any tumor specific therapy (chemotherapy or radiotherapy) before the resection. Twenty cases 253 diagnosed as inflammatory lesions and histologically confirmed with normal mucosal margins from 254 the resection specimens were included as control group in the $\mathrm{PPCR}$ analysis. The Ethics Committee 255 of the School of Medicine of Universidad del Desarrollo (FM-UDD CAS), National Cancer Institute of 256 Chile and Medicine School of Universidad Nacional de Cuyo (FCM-UNCuyo) approved this study 257 according to Declaration of Helsinki to experimentation with human subjects.

258 Histopathological analysis. The Oral biopsies were fixed in 10\% buffered formalin (Merck, USA), embedded in paraffin (Merck), and sectioned. Tissue sections of $4 \mu \mathrm{m}$ were deparaffinized with

260 Neoclear (Merck), rehydrated with graded alcohols, stained with hematoxylin-eosin (H\&E, Merck),

261 and visualized with a light microscope (DM2000; Leica, Germany). Images were captured with a 262 digital camera (DFC295; Leica). Samples were classified according to the revised criteria given by 263 the World Health Organization (2005). Three independent observers performed histological analyses 264 blind; one of them is a pathologist expert in oral diseases ${ }^{56,57}$.

265 Immunohistofluorescence analysis. Tissue sections of $4 \mu \mathrm{m}$ were deparaffinized, rehydrated, 266 blocked with 5\% FBS (Gibco, USA) dissolved in PBS 1X (Gibco, USA) and incubated overnight at 4 $267{ }^{\circ} \mathrm{C}$ with a dilution 1:50 of antibodies for anti-SPINK7 (Abcam, ab122326, USA), anti-HER2 (BD 268 Pharmigen $^{\text {TM }}$, \#554299, USA), anti-p53 (Abcam, (PAb 1801 ab28, USA) and anti-pRB (8516S, Cell 269 signaling, USA). Then, samples were washed with PBS $1 \mathrm{X}$ and incubated two hours at room 270 temperature with a dilution 1:400 of Alexa488-conjugated goat anti-mouse IgG or Alexa 555271 conjugated rabitt anti-mouse IgG (Cell Signaling, USA). Cross-reactivity of the secondary antibody 272 was tested incubating samples without the primary antibody. Nuclei were counterstained with a 273 dilution 1:1500 of DAPI (Sigma, Aldrich) in PBS 1X. Samples were embedded in fluorescence 274 mounting medium S3023 (Dako cytomation, USA) and scanned in a confocal microscope (Olympus). 275 Five representative optical sections by sample ( $n=6 /$ group) were photographed using 60X 276 magnification. The images obtained per field of each sample, were processed with the same 277 conditions and the positive protein signal (pixels intensity) was analyzed and quantified using Fiji 278 Image J software (NIH, USA) ${ }^{56,57}$.

279 Confocal microscopy analysis A Gaussian filter of 1 was applied and a constant background value 280 of 150 was subtracted for each image. The same threshold value was set for each channel including 
the structures of interest and the corresponding masks were obtained. The yellow pixels (red and green pixels overlap) versus the total pixels were quantified and the colocalization was measured with Coloc2 plugin (Fiji ImageJ) ${ }^{51}$.

284 Gene expression analysis Total RNA was isolated from the oral biopsies. The mRNA was purified using RNEasy PlusMini Kit (Qiagen, Germany). Contaminating genomic DNA was degraded with 1 $\mathrm{U}$ of DNAse RQ1 (Promega). One $\mu \mathrm{g}$ of RNA was reverse transcribed for $60 \mathrm{~min}$ at $42{ }^{\circ} \mathrm{C}$ using 200 $\mathrm{U}$ M-MLV reverse transcriptase (Invitrogen) and $0.5 \mu \mathrm{M}$ oligo-dT primers (Invitrogen). Real time PCR was performed in a final volume of $10 \mu \mathrm{L}$ containing $50 \mathrm{ng}$ of cDNA, Power SYBR Green PCR master mix (Life Technologies, Grand Island, NY) and $0.5 \mu \mathrm{M}$ of each specific primer, using the Step One Plus PCR system (Life Technologies). Controls without reverse transcriptase were included. Amplicons were analyzed according to their size and melting temperature (Supplementary Table 1,

292 S1). To normalize data, 18S RNA and $\beta$-actin were used as reference genes. The RNA level of a 293 target gene was calculated using the $2 \Delta \mathrm{Ct}$ method and graphed as fold change ${ }^{58}$.

294 Gene expressions TCGA profile. The data studied was programmatically extracted from the publicly 295 available data set of OSCC from The Cancer Genome Atlas Project (TCGA) on May, 2019 using the recount2 platform (https://jhubiostatistics.shinyapps.io/recount/). Non-standardized RNASeq gene expression levels from 548 samples were downloaded. Samples from oral cavity were selected obtaining a final subset of 332 tumor samples and 32 non-tumoral tissue samples. RNA expression levels were evaluated for 6 genes (NFKB1, RB1, TP53, ERBB2, CYP4B1, SPINK7). Crude counts were scaled by the total coverage of the sample (area under the curve, 'AUC') and differential gene expression analysis (DGE) was performed using the generalized linear model method of the EdgeR $\mathrm{R}$ package comparing non-tumor versus tumor samples ${ }^{59} . \log _{2}$ Fold change values were obtained associated with exact p-values and False Discovery Rate values (FDR). To evaluate gene expression correlation, data was transformed using Voom conversion from the $\mathrm{R}$ limma package, allowing normal linear modeling of the RNA counts. Afterwards, pairwise Pearson's product-moment correlation analysis was performed for the aforementioned genes and $p$-values were calculated ${ }^{50}$.

Gene mutations TCGA profile. The mutational analysis of OSCC, data was programmatically downloaded using the TCGA biolinks package of Bioconductor ${ }^{60}$. Mutation Annotation Format (MAF) files with aggregated mutation information generated from whole-exome sequencing were downloaded. From 546 samples of Head and Neck cancer, 329 samples of OSCC were obtained.

311 The maftools Bioconductor package was used to analyze and visualize the MAF files ${ }^{61}$. An Oncoplot 312 was drawn showing the variants (SNP) of the 15 most mutated genes in OSCC, followed by 5 genes 313 of interest (RB1, ERBB2, NFKB1, CYP4B1 and SPINK7) ${ }^{50}$.

314 Statistical analysis. The population distribution of the samples from our patients was non315 parametric. Comparisons of gene and protein expression among the groups were performed using 316 One-way Kruskal-Wallis test and Dunn's test as post-test. Stat Graph Prism 5.0 software was used 317 for statistical analysis. Data are presented as median \pm SEM, and $p<0.05$ was considered statistically 318 significative. 
1 Torre, L. A. et al. Global cancer statistics, 2012. CA: a cancer journal for clinicians 65, 87-108, doi:10.3322/caac.21262 (2015).

2 Grandi, C. et al. Prognostic significance of lymphatic spread in head and neck carcinomas: therapeutic implications. Head \& neck surgery 8, 67-73 (1985).

3 Fillies, T. et al. Catenin expression in T1/2 carcinomas of the floor of the mouth. International Journal of Oral and Maxillofacial Surgery 34, 907-911, doi:https://doi.org/10.1016/j.ijom.2005.03.010 (2005).

4 Rivera, C., Oliveira, A. K., Costa, R. A. P., De Rossi, T. \& Paes Leme, A. F. Prognostic biomarkers in oral squamous cell carcinoma: A systematic review. Oral oncology 72, 38-47, doi:10.1016/j.oraloncology.2017.07.003 (2017).

5 Ramaekers, F. C. et al. Coexpression of keratin- and vimentin-type intermediate filaments in human metastatic carcinoma cells. Proceedings of the National Academy of Sciences of the United States of America 80, 2618-2622, doi:10.1073/pnas.80.9.2618 (1983).

6 Brandwein-Gensler, M. et al. Oral squamous cell carcinoma: histologic risk assessment, but not margin status, is strongly predictive of local disease-free and overall survival. Am J Surg Pathol 29, 167-178, doi:10.1097/01.pas.0000149687.90710.21 (2005).

7 Almangush, A. et al. Depth of invasion, tumor budding, and worst pattern of invasion: prognostic indicators in early-stage oral tongue cancer. Head Neck 36, 811-818, doi:10.1002/hed.23380 (2014).

8 Sethi, S., Ali, S., Philip, P. A. \& Sarkar, F. H. Clinical advances in molecular biomarkers for cancer diagnosis and therapy. International journal of molecular sciences 14, 14771-14784, doi:10.3390/ijms140714771 (2013).

9 Hanahan, D. \& Weinberg, R. A. Hallmarks of cancer: the next generation. Cell 144, 646-674 (2011).

10 Hanahan, D. \& Weinberg, R. A. The hallmarks of cancer. Cell 100, 57-70 (2000).

11 Imai, K. et al. Immunolocalization of desmoglein and intermediate filaments in human oral squamous cell carcinomas. Head \& neck 17, 204-212 (1995).

12 Cui, Y., Bi, M., Su, T., Liu, H. \& Lu, S.-H. Molecular cloning and characterization of a novel esophageal cancer related gene. International journal of oncology 37, 1521-1528 (2010).

$13 \mathrm{Su}, \mathrm{T}$., Liu, H. \& Lu, S. Cloning and identification of cDNA fragments related to human esophageal cancer. Zhonghua zhong liu za zhi [Chinese journal of oncology] 20, 254-257 (1998).

14 Chui, X. et al. Immunohistochemical expression of the c-kit proto-oncogene product in human malignant and non-malignant breast tissues. British journal of cancer 73, 1233-1236, doi:10.1038/bjc.1996.236 (1996).

15 Engels, K. et al. Dynamic intracellular survivin in oral squamous cell carcinoma: underlying molecular mechanism and potential as an early prognostic marker. The Journal of pathology 211, 532-540, doi:10.1002/path.2134 (2007).

16 Clevers, H. Wht/beta-catenin signaling in development and disease. Cell 127, 469-480, doi:10.1016/j.cell.2006.10.018 (2006).

17 Bernardes, V. F., Gleber-Netto, F. O., Sousa, S. F., Silva, T. A. \& Aguiar, M. C. Clinical significance of EGFR, Her-2 and EGF in oral squamous cell carcinoma: a case control study. Journal of experimental \& clinical cancer research : CR 29, 40, doi:10.1186/1756-9966-29-40 (2010).

18 Press, M. F. \& Lenz, H. J. EGFR, HER2 and VEGF pathways: validated targets for cancer treatment. Drugs 67, 2045-2075, doi:10.2165/00003495-200767140-00006 (2007).

19 Burgess, A. W. et al. An open-and-shut case? Recent insights into the activation of EGF/ErbB receptors. Molecular cell 12, 541-552, doi:10.1016/s1097-2765(03)00350-2 (2003).

20 Feng, Y. et al. Breast cancer development and progression: Risk factors, cancer stem cells, signaling pathways, genomics, and molecular pathogenesis. Genes Dis 5, 77-106, doi:10.1016/j.gendis.2018.05.001 (2018).

21 Bernardes, V. F., Gleber-Netto, F. O., Sousa, S. F., Silva, T. A. \& Aguiar, M. C. F. Clinical significance of EGFR, Her-2 and EGF in oral squamous cell carcinoma: a case control study. Journal of Experimental \& Clinical Cancer Research 29, 40, doi:10.1186/1756-9966-29-40 (2010).

22 Sasahira, T. \& Kirita, T. Hallmarks of Cancer-Related Newly Prognostic Factors of Oral Squamous Cell Carcinoma. International journal of molecular sciences 19, doi:10.3390/ijms19082413 (2018).

23 Zheng, L.-S. et al. SPINK6 promotes metastasis of nasopharyngeal carcinoma via binding and activation of epithelial growth factor receptor. Cancer research (2016).

24 Kim, M. S., Li, S. L., Bertolami, C. N., Cherrick, H. M. \& Park, N. H. State of p53, Rb and DCC tumor suppressor genes in human oral cancer cell lines. Anticancer research 13, 1405-1413 (1993). 
25 Choi, S. \& Myers, J. Molecular pathogenesis of oral squamous cell carcinoma: implications for therapy. Journal of dental research 87, 14-32 (2008).

26 Daniela Adorno-Farias, J. P. A., Montserrat Reyes, Ana Ortega, Blanca Urzúa, Lilian Jara, Alfredo Molina, José Jara, Jean Nunes dos Santos, Sandra Tarquínio, Ricardo Fernández-Ramires. Alteraciones genéticas de la mucosa oral hacia la transformación maligna. Acta Odontologica Venezolana 55 (2017).

27 Hanahan, D. \& Weinberg, R. A. Hallmarks of cancer: the next generation. Cell 144, 646-674, doi:10.1016/j.cell.2011.02.013 (2011).

28 Network, C. G. A. Comprehensive genomic characterization of head and neck squamous cell carcinomas. Nature 517, 576-582, doi:10.1038/nature14129 (2015).

29 Neskey, D. M. et al. Evolutionary Action Score of TP53 Identifies High-Risk Mutations Associated with Decreased Survival and Increased Distant Metastases in Head and Neck Cancer. Cancer research 75, 1527-1536, doi:10.1158/0008-5472.can-14-2735 (2015).

30 Osman, A. A. et al. Evolutionary Action Score of TP53 Coding Variants Is Predictive of Platinum Response in Head and Neck Cancer Patients. Cancer research 75, 1205-1215, doi:10.1158/00085472.can-14-2729 (2015).

31 Sandulache, V. C. et al. High-Risk TP53 Mutations Are Associated with Extranodal Extension in Oral Cavity Squamous Cell Carcinoma. Clinical cancer research : an official journal of the American Association for Cancer Research 24, 1727-1733, doi:10.1158/1078-0432.ccr-17-0721 (2018).

32 de Oliveira, L. R., Ribeiro-Silva, A. \& Zucoloto, S. Prognostic impact of p53 and p63 immunoexpression in oral squamous cell carcinoma. Journal of oral pathology \& medicine : official publication of the International Association of Oral Pathologists and the American Academy of Oral Pathology 36, 191-197, doi:10.1111/j.1600-0714.2007.00517.x (2007).

33 Cheng, X., Shen, Z., Yang, J., Lu, S.-H. \& Cui, Y. ECRG2 disruption leads to centrosome amplification and spindle checkpoint defects contributing chromosome instability. Journal of Biological Chemistry 283, 5888-5898 (2008).

34 Thomas, S., Balan, A. \& Balaram, P. The expression of retinoblastoma tumor suppressor protein in oral cancers and precancers: A clinicopathological study. Dent Res J (Isfahan) 12, 307-314, doi:10.4103/1735-3327.161427 (2015).

35 Pande, P., Mathur, M., Shukla, N. K. \& Ralhan, R. pRb and p16 protein alterations in human oral tumorigenesis. Oral oncology 34, 396-403, doi:10.1016/s1368-8375(98)00024-4 (1998).

36 Postler, T. S. \& Ghosh, S. Bridging the gap: A regulator of NF- $\mathrm{kB}$ linking inflammation and cancer. Journal of Oral Biosciences 57, 143-147, doi:https://doi.org/10.1016/i.job.2015.05.001 (2015).

37 Jimi, E. et al. NF- $\mathrm{KB}$ acts as a multifunctional modulator in bone invasion by oral squamous cell carcinoma. Oral Science International 13, 1-6, doi:https://doi.org/10.1016/S1348-8643(15)00038$\underline{5}(2016)$.

$38 \mathrm{Xu}, \mathrm{X}$., Zhang, X. A. \& Wang, D. W. The roles of CYP450 epoxygenases and metabolites, epoxyeicosatrienoic acids, in cardiovascular and malignant diseases. Adv Drug Deliv Rev 63, 597 609, doi:10.1016/j.addr.2011.03.006 (2011).

39 Zelasko, S., Arnold, W. R. \& Das, A. Endocannabinoid metabolism by cytochrome P450 monooxygenases. Prostaglandins Other Lipid Mediat 116-117, 112-123, doi:10.1016/j.prostaglandins.2014.11.002 (2015).

40 Pikuleva, I. A. \& Waterman, M. R. Cytochromes p450: roles in diseases. The Journal of biological chemistry 288, 17091-17098, doi:10.1074/jbc.R112.431916 (2013).

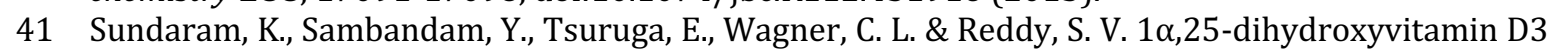
modulates CYP2R1 gene expression in human oral squamous cell carcinoma tumor cells. Horm Cancer 5, 90-97, doi:10.1007/s12672-014-0170-5 (2014).

42 Creighton, C. J. Making Use of Cancer Genomic Databases. Curr Protoc Mol Biol 121, 19.14.1119.14.13, doi:10.1002/cpmb.49 (2018).

43 Zheng, L.-S. et al. SPINK6 Promotes Metastasis of Nasopharyngeal Carcinoma via Binding and Activation of Epithelial Growth Factor Receptor. Cancer research 77, 579-589, doi:10.1158/00085472.CAN-16-1281 (2017).

44 Woolgar, J. A. \& Triantafyllou, A. Pitfalls and procedures in the histopathological diagnosis of oral and oropharyngeal squamous cell carcinoma and a review of the role of pathology in prognosis. Oral oncology 45, 361-385 (2009).

45 Cervino, G. et al. Molecular Biomarkers Related to Oral Carcinoma: Clinical Trial Outcome Evaluation in a Literature Review. Disease markers 2019, 8040361, doi:10.1155/2019/8040361 (2019).

46 Williams, H. K. Molecular pathogenesis of oral squamous carcinoma. Molecular Pathology 53, 165$172(2000)$. 
47 Zini, A., Czerninski, R. \& Sgan - Cohen, H. D. Oral cancer over four decades: epidemiology, trends, histology, and survival by anatomical sites. Journal of oral pathology \& medicine 39, 299-305 (2010).

48 Napier, S. S. \& Speight, P. M. Natural history of potentially malignant oral lesions and conditions: an overview of the literature. Journal of oral pathology \& medicine 37, 1-10 (2008).

49 Speight, P. M. \& Farthing, P. M. The pathology of oral cancer. British Dental Journal 225, 841-847, doi:10.1038/sj.bdj.2018.926 (2018).

50 Zoppino, F. C. M., Guerrero-Gimenez, M. E., Castro, G. N. \& Ciocca, D. R. Comprehensive transcriptomic analysis of heat shock proteins in the molecular subtypes of human breast cancer. BMC cancer 18, 700-700, doi:10.1186/s12885-018-4621-1 (2018).

51 Moser, B., Hochreiter, B., Herbst, R. \& Schmid, J. A. Fluorescence colocalization microscopy analysis can be improved by combining object-recognition with pixel-intensity-correlation. Biotechnol J 12, 1600332, doi:10.1002/biot.201600332 (2017).

52 Vats, S., Ganesh, M. \& Agarwal, A. Human epidermal growth factor receptor 2 neu expression in head and neck squamous cell cancers and its clinicopathological correlation: Results from an Indian cancer center. Indian Journal of Pathology and Microbiology 61, 313-318, doi:10.4103/03774929.236599 (2018).

53 Mazzoccoli, G. et al. A primary tumor gene expression signature identifies a crucial role played by tumor stroma myofibroblasts in lymph node involvement in oral squamous cell carcinoma. Oncotarget 8 (2017).

54 Goldstein, A. S., Zong, Y. \& Witte, O. N. A Two-Step Toward Personalized Therapies for Prostate Cancer. Science Translational Medicine 3, 72ps77, doi:10.1126/scitranslmed.3002169 (2011).

55 Lakshminarayana, S. et al. Molecular pathways of oral cancer that predict prognosis and survival: A systematic review. J Carcinog 17, 7-7, doi:10.4103/jcar.JCar_17_18 (2018).

56 Bruna, F., Arango-Rodríguez, M., Plaza, A., Espinoza, I. \& Conget, P. The administration of multipotent stromal cells at precancerous stage precludes tumor growth and epithelial dedifferentiation of oral squamous cell carcinoma. Stem Cell Research 18, 5-13, doi:https://doi.org/10.1016/j.scr.2016.11.016 (2017).

57 Bruna, F., Plaza, A., Arango, M., Espinoza, I. \& Conget, P. Systemically administered allogeneic mesenchymal stem cells do not aggravate the progression of precancerous lesions: a new biosafety insight. Stem Cell Research \& Therapy 9, 137 (2018).

58 Schmittgen, T. D. \& Livak, K. J. Analyzing real-time PCR data by the comparative CT method. Nature Protocols 3, 1101-1108, doi:10.1038/nprot.2008.73 (2008).

59 Wang, T., Li, B., Nelson, C. E. \& Nabavi, S. Comparative analysis of differential gene expression analysis tools for single-cell RNA sequencing data. BMC Bioinformatics 20, 40-40, doi:10.1186/s12859-019-2599-6 (2019).

60 Colaprico, A. et al. TCGAbiolinks: an R/Bioconductor package for integrative analysis of TCGA data. Nucleic acids research 44, e71-e71, doi:10.1093/nar/gkv1507 (2016).

61 Mayakonda, A., Lin, D.-C., Assenov, Y., Plass, C. \& Koeffler, H. P. Maftools: efficient and comprehensive analysis of somatic variants in cancer. Genome Res 28, 1747-1756, doi:10.1101/gr.239244.118 (2018).

Acknowledgments. To Instituto Nacional del Cancer Chile; CIICOM; Clínica Montes; SEMEB, UNCuyo; IMBECU CCT-Mendoza CONICET; CMR, UDD-CAS; Facultad de Odontología, UMayor.

Author's contributions. The authors of the present work have made substantial contribution to the article. RFR and FAB contributed to the conception and design of the work. FAB wrote the main manuscript text. GP, FVG, WAGA, HFM, JMRP, VAG, SEG, RFR and FAB contributed to the acquisition, analysis and interpretation of data obtained from patient's biopsies. RFR and FAB prepared figures 1-2; 4-5. MEGG, JMFM and FCMZ contributed to the database acquisition, in silico analysis and interpretation of TGCA data obtained from the USA Cancer Atlas and prepared the figure 3. RFR, FAB, MEE and RWC contributed with the discussion section.

All the authors reviewed the manuscript. 


\section{Funding}

491 This work was supported by: PI UDD-CAS N20141001185304708249 grant (FAB); Foundation JA 492 Roemmers (FAB) and Project FDP Universidad Mayor RFR (PEP I-2019081) (RFR).

493 Ethics approval and consent to participate

494 The Ethics Committee of the School of Medicine of Universidad del Desarrollo (FM-UDD CAS),

495 National Cancer Institute of Chile and Medicine School of Universidad Nacional de Cuyo (FCM496 UNCuyo) approved this study according to Declaration of Helsinki to experimentation with human 497 subjects.

\section{Conflict of interest}

499 The authors declare that they have no competing interests.

500

501

502

503

504

\section{Tables}

\begin{tabular}{|l|c|c|}
\hline Population of study data & $\begin{array}{l}\text { Number of } \\
\text { Patients with } \\
\text { OscC lesions } \\
\text { (n) }\end{array}$ & $\begin{array}{l}\text { Percentage of } \\
\text { Patients with oscc } \\
\text { lesions (\%) }\end{array}$ \\
\hline \multicolumn{3}{|c|}{ Age } \\
\hline < 40 years old & 12 & $15 \%$ \\
\hline $41-59$ years old & 32 & $40 \%$ \\
\hline$>60$ years old & 37 & $45 \%$ \\
\hline \multicolumn{3}{|c|}{ Gender } \\
\hline Female & 32 & $40 \%$ \\
\hline Male & 49 & $60 \%$ \\
\hline \multicolumn{3}{|c|}{ Smoke habits } \\
\hline No & 24 & $30 \%$ \\
\hline Light smokers (<5/dia) & 16 & $20 \%$ \\
\hline Heavy smokers (>10/dia) & 41 & $40 \%$ \\
\hline Non specific & 1 & $10 \%$ \\
\hline
\end{tabular}

Table 1. Socio-demographics data of study population

\section{Figures \& legends}

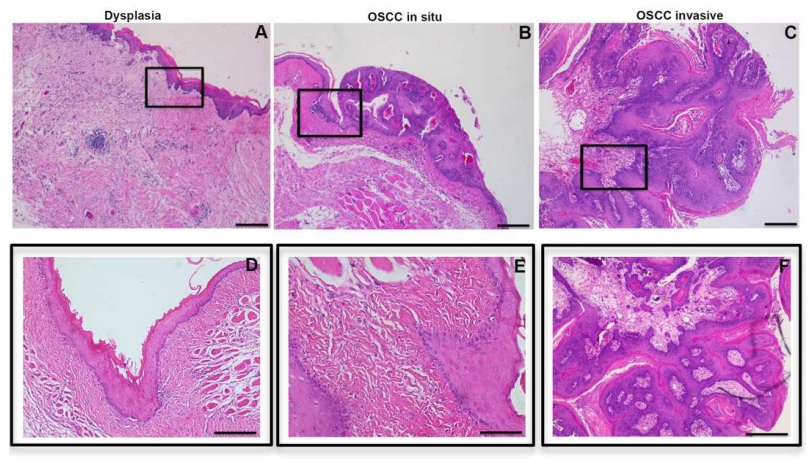

508 Figure 1. OSCC stages H\&E analysis. Oral biopsies of patients were analyzed by H\&E and 509 classified into dysplasia (Figures $1 A$ and 1D), less invasive OSCC (Figures 1B and 1E) and highly 510 invasive OSCC (Figures $1 \mathrm{C}$ and $1 \mathrm{~F}$ ) according to the changes in the epithelium.

511 The Figures 1A and 1D shown that in all dysplasia cases at different magnification. Regarding the 512 tissue did not show loss of basal membrane continuity or presence of epithelial cells invading the

513 stroma, although an increase in epithelial cell layers and presence of mild leukocyte infiltrate was 514 observed. 
515 The biopsies of patients with OSCC both less (Figures 1B and $1 \mathrm{E}$ ) and highly invasive cases (Figures

$5161 \mathrm{C}$ and $1 \mathrm{~F}$ ), showed at different magnification more than 5 layers of epithelial cells, hyperchromatism,

517 presence of keratin pearls, loss of continuity of the basement membrane and severe leukocyte

518 infiltrate were seen. In the highly invasive OSCC group, epithelial cell nests were observed in the

519 stroma and severe epithelium disorganization, accompanied of leucocyte infiltration of high grade

520 (Figures 1C-F).
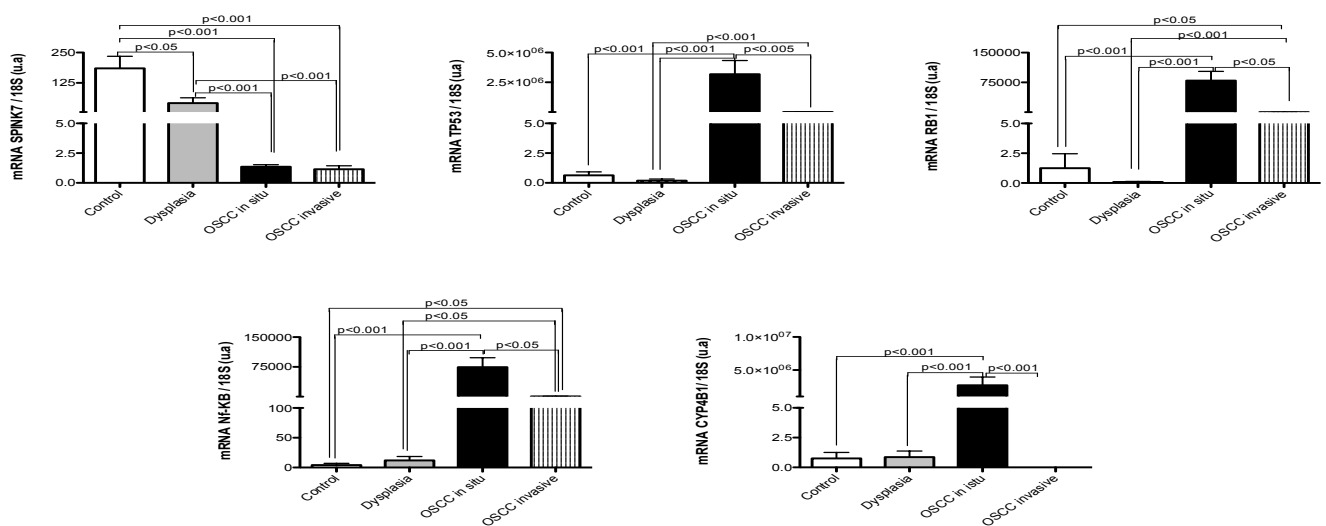

Figure 2. SPINK7, TP53, RB1, NFKB and CYP4B1 gene expression change among the OSCC

stages. The graph bar showed the gene expression evaluated by qPCR of each group (normal, dysplasia, less invasive and highly invasive OSCC) and the results were expressed as arbitrary units. The differences were considered statistically significance with $P$ values of $\left({ }^{*} P<0.05,{ }^{* *} P<0.01\right.$ and $\left.{ }^{* * *} P<0.001\right)$.

A.

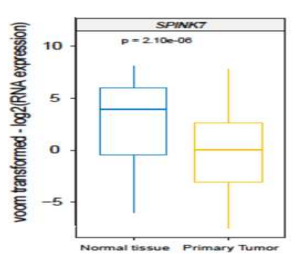

B.

Figure 3. SPINK7 gene expression and mutational profile in a cohort of patients from the TCGA database. A) Box-plot derived of TCGA gene expression analysis of SPINK7 from 581 samples of normal group (box-plot blue) vs primary tumors group (box-plot yellow). B) The Oncoplot graph shows the profile of oral cancer mutations taking into account the fifteen genes with the highest number of mutations (SNP) followed by five genes of interest (RB1, ERBB2/HER2, NFKB1, CYP4B1 and SPINK7). Each column represents a sample of oral cancer and each color represents a type of mutation variant. On the right, the size of each bar represents the frequency of mutations throughout 
all samples and the percentage of samples that have this mutated gene. Variants annotated as Multi_Hit are those genes that are mutated more than once in the same sample. In the upper part the number of mutations that each sample has graphed.
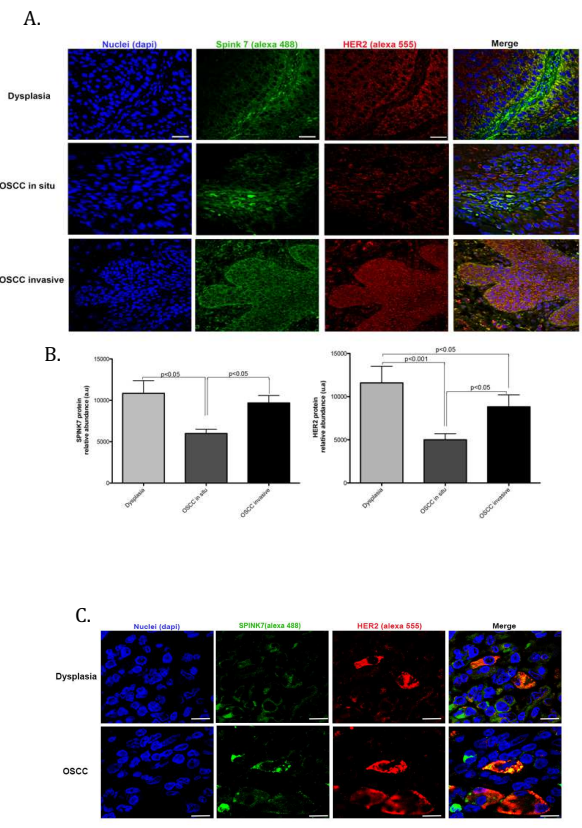

Figure 4. SPINK7 and HER2 proteins analysis among the OSCC stages. A) Immunohistofluorescence of SPINK7 (green) and HER2 (red) proteins evaluated in biopsies of dysplasia, less invasive and highly invasive OSCC. Nuclei were stained with Dapi (blue).

The Figure 4B show the graphs bar of the quantitative analysis of pixels intensity (green=SPINK7 and red=HER2) assessed by Image $\mathrm{J}$.

The Figure 4C) show the images at high magnification (120X) among the OSCC stages, showing the close localization of both proteins' signals through overlap image (yellow pixels), Representative images by group, $\mathrm{n}=6$. White bar $=50 \mu \mathrm{m}$. The differences were considered statistically significance with $P$ values of $\left({ }^{*} P<0.05\right.$ and $\left.{ }^{* * *} P<0.001\right)$.

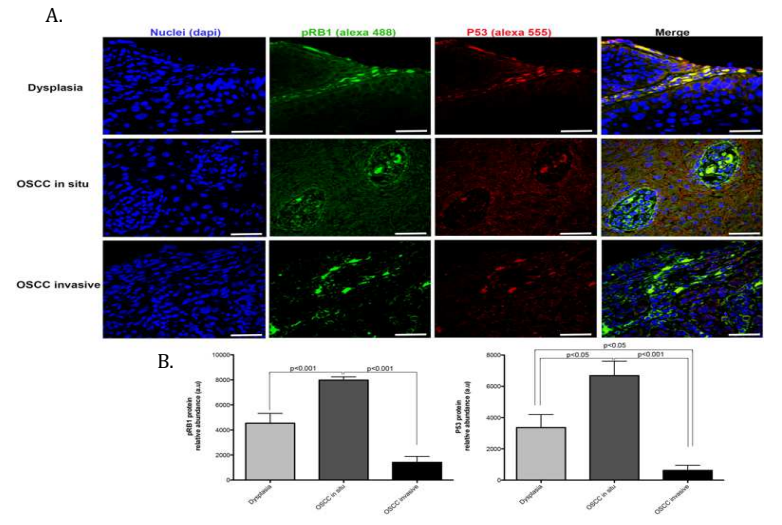

Figure 5. pRB1 and P53 proteins analysis among the OSCC stages. A) Immunohistofluorescence of both proteins, evaluated in biopsies of dysplasia, less invasive and highly invasive OSCC. B) 
573 Graphs bar show quantitative analysis of pixels intensity (green=pRB1 and red=P53) assessed by

574 ImageJ. Representative images by group, $n=6 / g r o u p$. White bar $=50 \mu \mathrm{m}$. The differences were 575 considered statistically significance with $P$ values of $\left({ }^{*} P<0.05\right.$ and $\left.{ }^{* * *} P<0.001\right)$. 


\section{Figures}
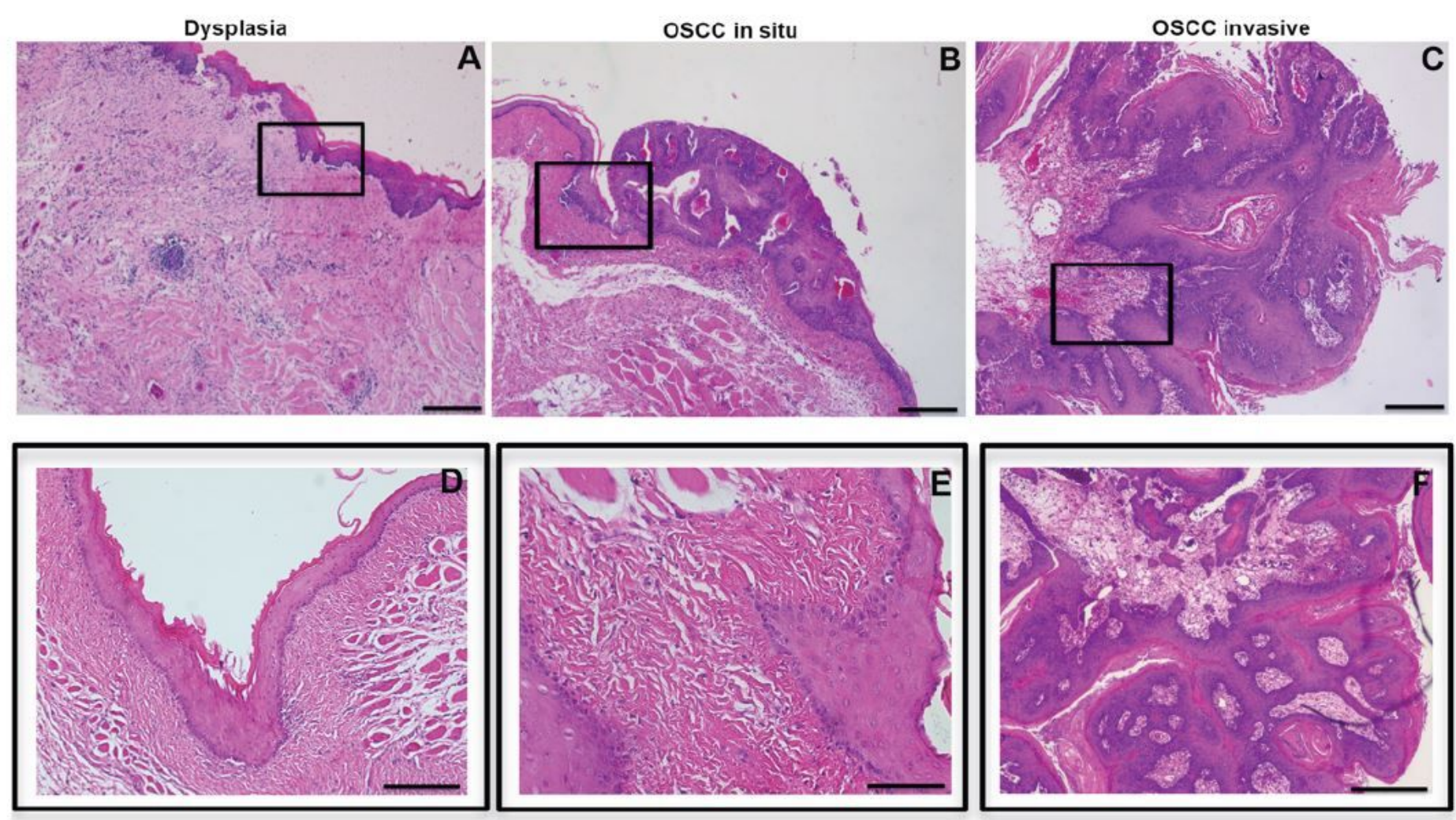

\section{Figure 1}

OSCC stages H\&E analysis. Oral biopsies of patients were analyzed by H\&E and classified into dysplasia (Figures 1A and 1D), less invasive OSCC (Figures 1B and 1E) and highly invasive OSCC (Figures 1C and $1 \mathrm{~F}$ ) according to the changes in the epithelium. The Figures 1A and 1D shown that in all dysplasia cases at different magnification. Regarding the tissue did not show loss of basal membrane continuity or presence of epithelial cells invading the stroma, although an increase in epithelial cell layers and presence of mild leukocyte infiltrate was observed. The biopsies of patients with OSCC both less (Figures 1B and $1515 \mathrm{E}$ ) and highly invasive cases (Figures 1C and 1F), showed at different magnification more than 5 layers of epithelial cells, hyperchromatism, presence of keratin pearls, loss of continuity of the basement membrane and severe leukocyte infiltrate were seen. In the highly invasive OSCC group, epithelial cell nests were observed in the stroma and severe epithelium disorganization, accompanied of leucocyte infiltration of high grade (Figures 1C-F). 

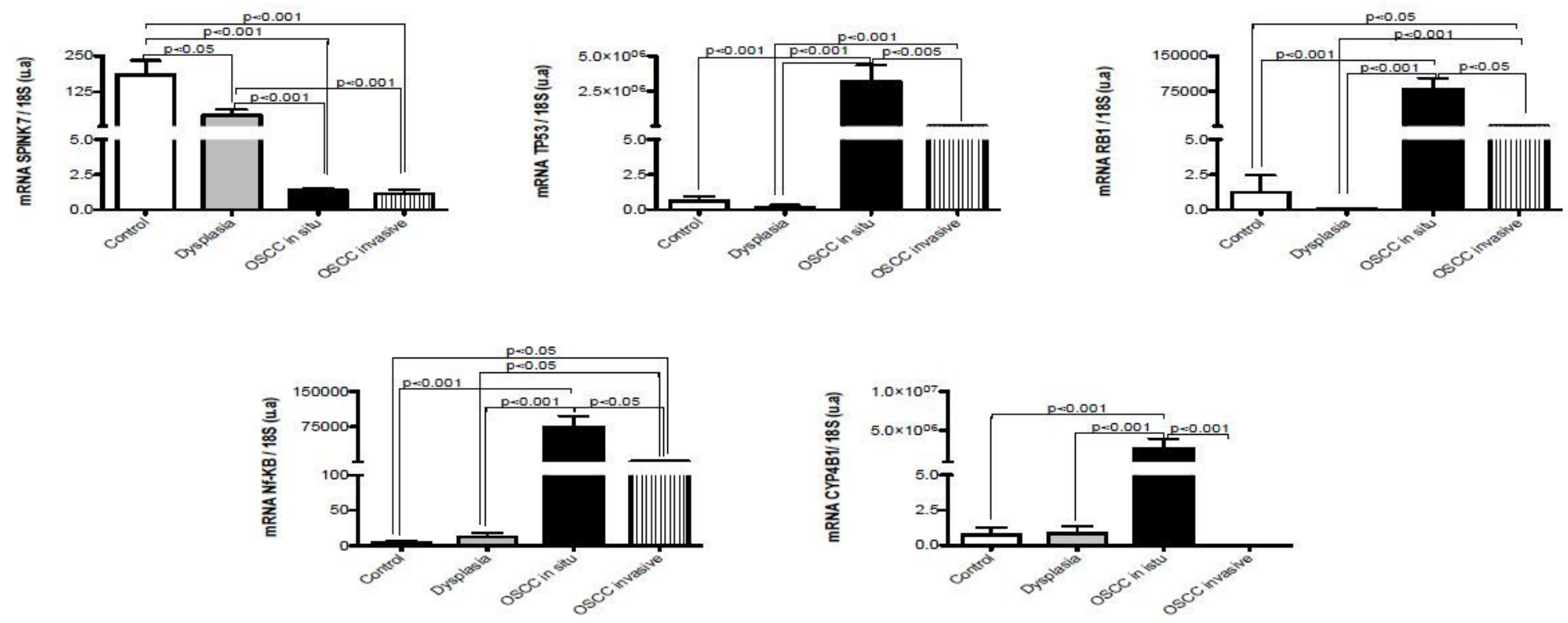

Figure 2

SPINK7, TP53, RB1, NFKB and CYP4B1 gene expression change among the OSCC stages. The graph bar showed the gene expression evaluated by qPCR of each group (normal, dysplasia, less invasive and highly invasive OSCC) and the results were expressed as arbitrary units. The differences were considered statistically significance with $P$ values of $\left(* P<0.05,{ }^{*} * P<0.01\right.$ and $\left.{ }^{*} * *<0.001\right)$.

A.

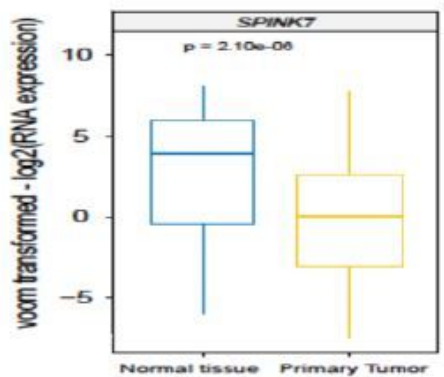

B.

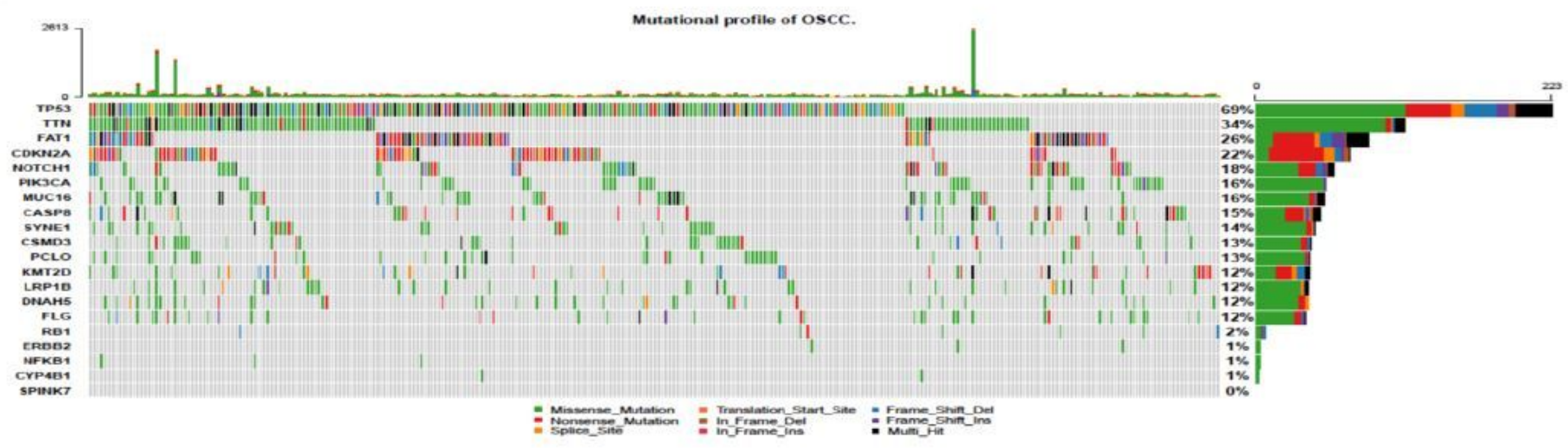

Figure 3 
SPINK7 gene expression and mutational profile in a cohort of patients from the TCGA database. A) Boxplot derived of TCGA gene expression analysis of SPINK7 from 581 samples of normal group (box-plot blue) vs primary tumors group (box-plot yellow). B) The Oncoplot graph shows the profile of oral cancer mutations taking into account the fifteen genes with the highest number of mutations (SNP) followed by five genes of interest (RB1, ERBB2/HER2, NFKB1, CYP4B1 and SPINK7). Each column represents a sample of oral cancer and each color represents a type of mutation variant. On the right, the size of each bar represents the frequency of mutations throughout all samples and the percentage of samples that have this mutated gene. Variants annotated as Multi_Hit are those genes that are mutated more than once in the same sample. In the upper part the number of mutations that each sample has graphed. 
A.

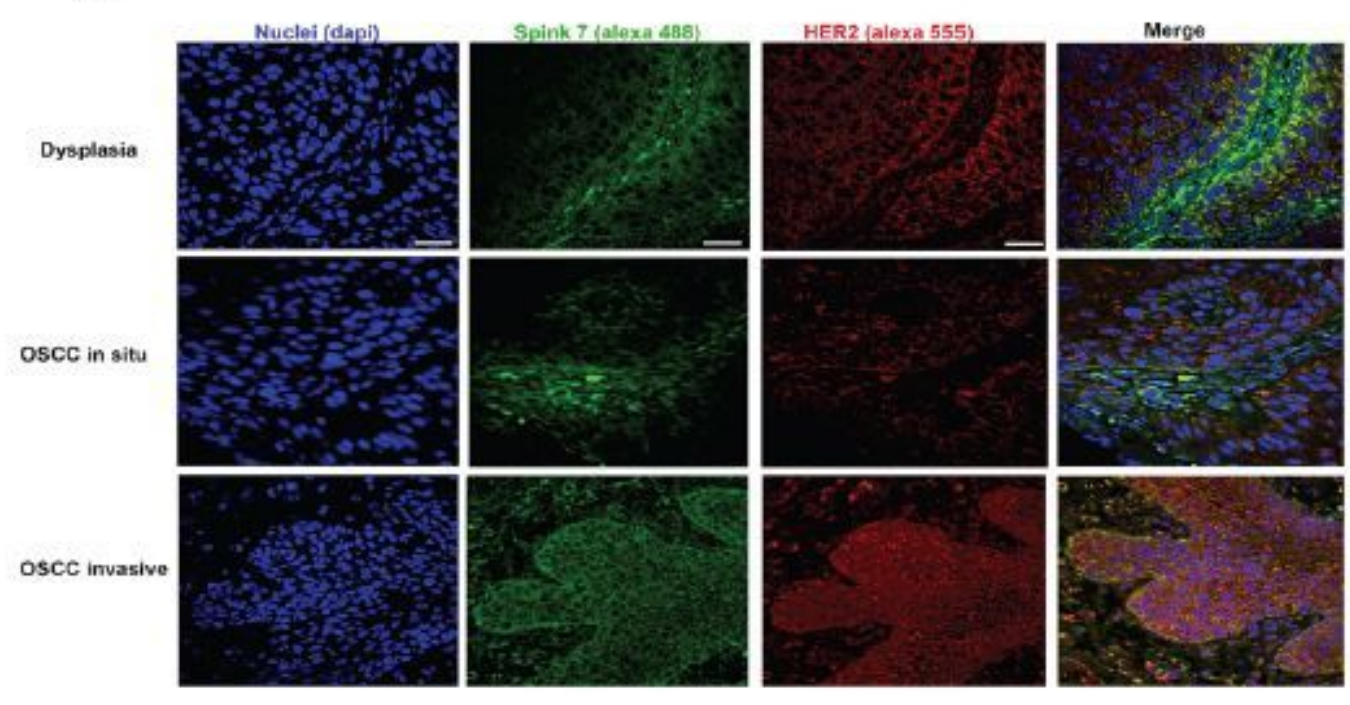

B.

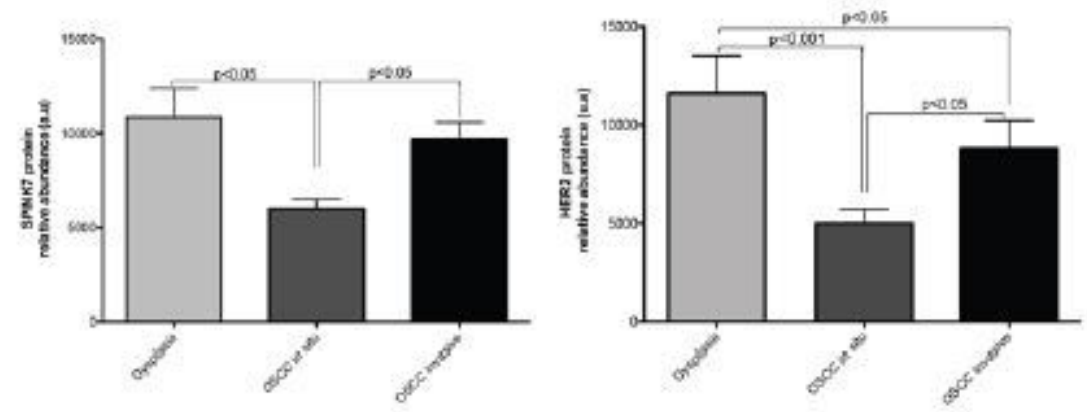

C.

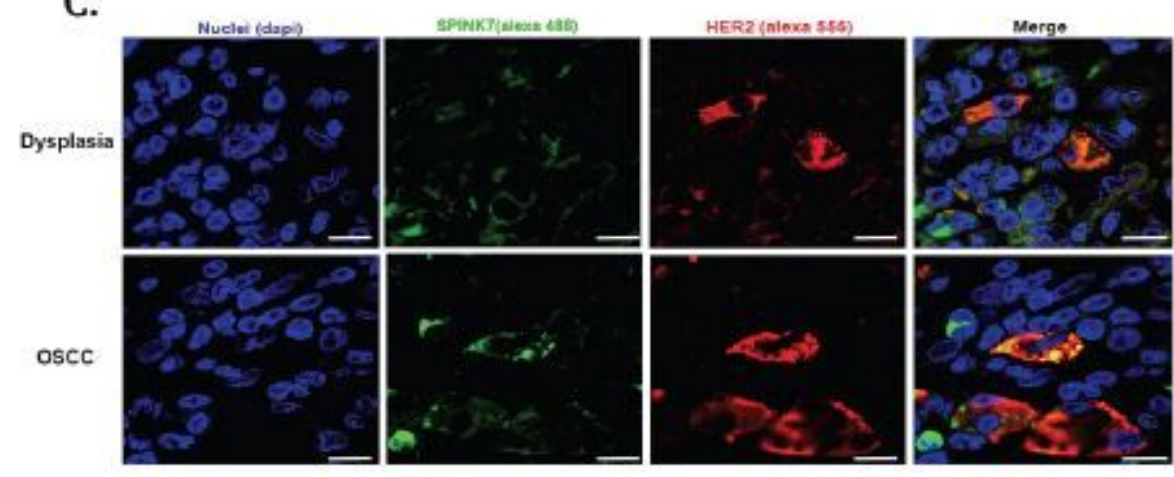

Figure 4

SPINK7 and HER2 proteins analysis among the OSCC stages. A) Immunohistofluorescence of SPINK7 (green) and HER2 (red) proteins evaluated in biopsies of dysplasia, less invasive and highly invasive OSCC. Nuclei were stained with Dapi (blue). The Figure 4B show the graphs bar of the quantitative analysis of pixels intensity (green=SPINK7 and red=HER2) assessed by Image J. The Figure 4C) show the images at high magnification (120X) among the OSCC stages, showing the close localization of both 
proteins' signals through overlap image (yellow pixels), Representative images by group, $n=6$. White bar $=$ $50 \mu \mathrm{m}$. The differences were considered statistically significance with $P$ values of $\left({ }^{\star} P<0.05\right.$ and $\star \star * P<0.001)$.

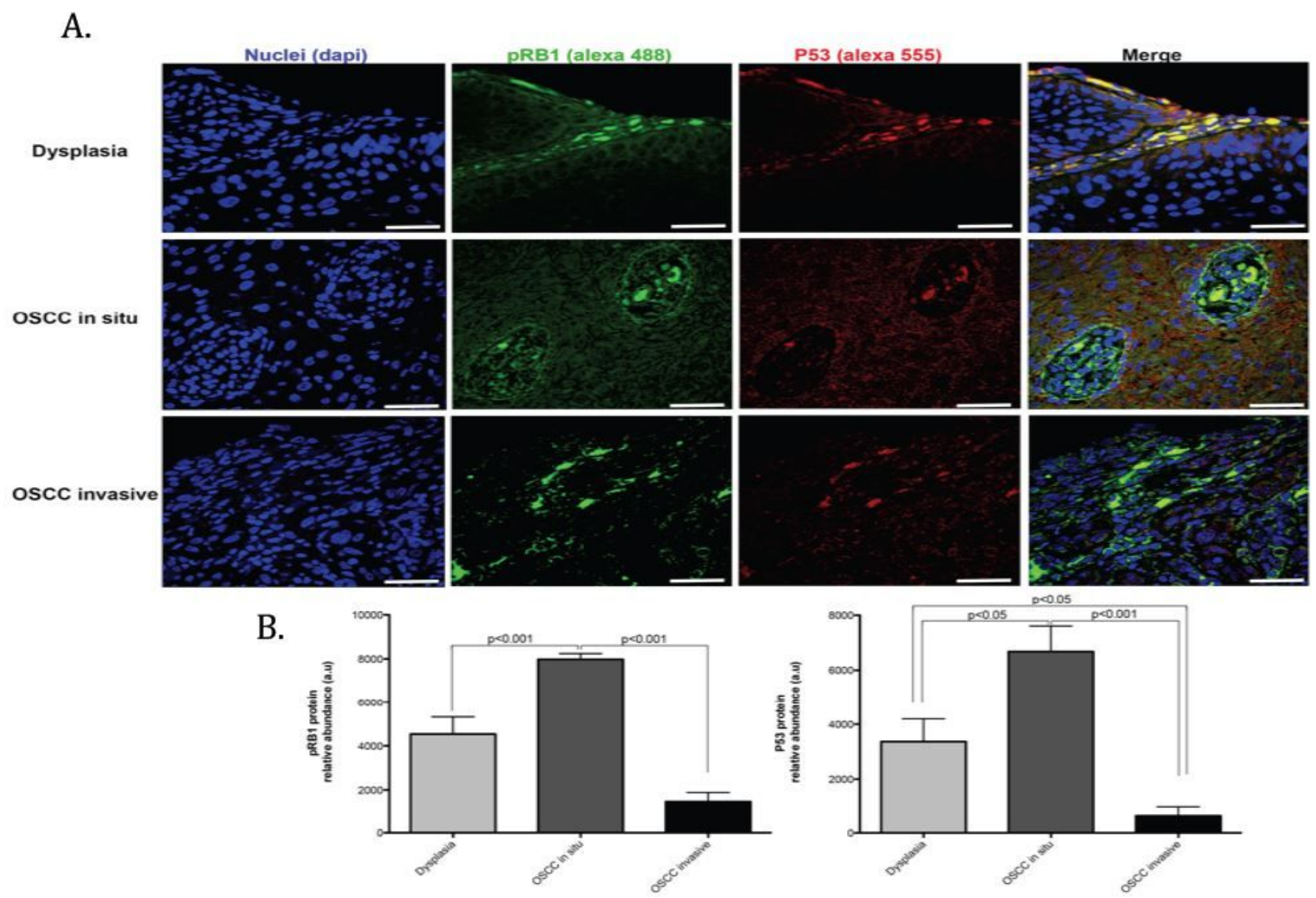

\section{Figure 5}

pRB1 and P53 proteins analysis among the OSCC stages. A) Immunohistofluorescence of both proteins, evaluated in biopsies of dysplasia, less invasive and highly invasive OSCC. B) Graphs bar show quantitative analysis of pixels intensity ( 573 green=pRB1 and red=P53) assessed by ImageJ. Representative images by group, $n=6 /$ group. White bar $=50 \mu \mathrm{m}$. The differences were considered statistically significance with $P$ values of $(* P<0.05$ and $* * * P<0.001)$.

\section{Supplementary Files}

This is a list of supplementary files associated with this preprint. Click to download.

- Pennacchiottietalsupplementarytable.docx 